\title{
Effect of prior cancer on survival outcomes for patients with pancreatic adenocarcinoma: a propensity score analysis
}

\author{
Chaobin $\mathrm{He}^{1+}$, Yu Zhang ${ }^{2 \dagger}$, Zhiyuan $\mathrm{Cai}^{1}$ and Xiaojun Lin $^{1 *}$ [0
}

\begin{abstract}
Background: With the increase in cancer survivors, more pancreatic ductal adenocarcinomas (PDACs) are developing as second primary cancers. Whether a prior cancer has an inferior impact on survival outcomes in patients with PDAC remains unknown, and the validity of criteria used to exclude patients with prior cancers in clinical trials needs to be determined. The aim of this study was to evaluate the prognostic factors and assess the survival impact of a prior cancer in patients with second primary PDAC.

Methods: Patients with PDAC were retrospectively selected from the Surveillance, Epidemiology, and End Results (SEER) database. Overall survival (OS) and cancer-specific mortality rates were compared between patients with and those without prior cancer.

Results: The data of 9235 patients with PDAC from 2004 to 2015 were retrieved from the SEER database, consisting of 438 (4.74\%) patients with a prior cancer and 8797 (95.26\%) patients without a prior cancer, the patients were then pair-matched using propensity score matching (PSM) analysis. The median OS rates were 7 months for both groups of patients with PDAC with and without prior cancer. These two groups of patients had similar survival rates and cancer-specific mortalities before and after the PSM analysis. In the multivariate analysis, a history of prior cancer was not a significant prognostic factor of OS in patients with PDAC.

Conclusions: Patients with PDAC who had a prior cancer had similar OS and cancer-specific mortality rates as those of patients without a prior cancer. The inclusion of patients with a prior cancer in the clinical trials of PDAC should be considered.
\end{abstract}

Keywords: Pancreatic ductal adenocarcinoma, History of prior cancer, Survival, Population-based study

\section{Background}

One-fourth of deaths have been attributed to cancers; however, an obvious decline (by 22\%) in the rate of cancer-related deaths was observed from 1991 to 2011 [1]. The number of cancer survivors is growing due to improved treatment outcomes. However, this result may lead to an increasing chance of developing second

\footnotetext{
* Correspondence: linxj@sysucc.org.cn

${ }^{+}$Chaobin He and Yu Zhang contributed equally to this work.

'Department of Hepatobiliary and Pancreatic Surgery, State Key Laboratory

of Oncology in South China, Collaborative Innovation Center for Cancer

Medicine, Sun Yat-sen University Cancer Center, Guangzhou 510060, People's

Republic of China

Full list of author information is available at the end of the article
}

primary malignant neoplasms (SPMs). It was reported that SPMs accounted for 17 to $19 \%$ of new cancer cases $[2,3]$. In addition, the morbidities are increasing year by year, and it is estimated that there may be more than 20 million cancer survivors who are at risk of SPMs by 2026 [4].

Pancreatic ductal adenocarcinoma (PDAC) is an aggressive and lethal disease with an annually increasing incidence. Along with an increased number of cancer survivors who are at a high risk of developing SPMs, PDAC is becoming increasingly frequently developed as a subsequent tumor $[5,6]$. Multiple studies have sought to evaluate the prognostic factors of patients with PDAC

(c) The Author(s). 2019 Open Access This article is distributed under the terms of the Creative Commons Attribution 4.0 International License (http://creativecommons.org/licenses/by/4.0/), which permits unrestricted use, distribution, and reproduction in any medium, provided you give appropriate credit to the original author(s) and the source, provide a link to the Creative Commons license, and indicate if changes were made. The Creative Commons Public Domain Dedication waiver (http://creativecommons.org/publicdomain/zero/1.0/) applies to the data made available in this article, unless otherwise stated. 
as the first primary cancer, while there are few data regarding patients with PDAC as the second primary cancer. Moreover, clinical trials are important for improving the survival of patients, but a history of prior cancer is one of the most commonly used exclusion criteria in clinical trials, which may be a huge treatment hurdle for a large proportion of patients with SPMs [7]. Given the sizable number of patients with a prior cancer, this exclusion criterion limits the generalizability of inclusion cases in clinical trials. Therefore, it is important to validate this exclusion criterion in clinical trials for patients with PDAC as a second primary cancer.

To address these issues, we aimed to evaluate the prognostic factors and to assess the survival impact of a prior cancer in patients with second primary PDAC using the Surveillance, Epidemiology, and End Results (SEER) database. The findings of this study may provide potential insight into the clinical management and surveillance of patients with PDAC who had a prior cancer.

\section{Methods \\ Patients}

The data of patients with PDAC from 2004 to 2015 were extracted from the SEER database, using the SEER*Stat software (v. 8.3.5). The study cohort consisted of patients with the following International Classification of Diseases for Oncology, Third Edition (ICD-O-3) histology codes 8140/3, 8144/3, 8255/3, 8261/3, and 8263/3, as well as the ICD-O-3 site codes C25.0, C25.1, C25.2, C25.3, C25.7, C25.8, and C25.9. For patients with prior cancers, ICD-O-3 was used to identify the types of primary solid tumors. Patients who were younger than 18 years, who did not have pathologically confirmed PDAC or who had missing information about clinical factors were excluded from this study.

\section{Data collection}

Records for age at diagnosis, gender, tumor size, tumor grade, tumor site, tumor-node-metastasis (TNM) stage, treatment, follow-up information, and causes of death were obtained using the SEER registries. The sequence numbers of all primary tumors of patients with PDAC were determined to ascertain whether they had a prior cancer. The time interval between the prior cancer and the index cancer was calculated, and a latency period of at least 6 months was adopted to avoid the possibility of synchronous metastases. The dataset from the SEER database that was generated and analyzed during the current study is available in the SEER dataset repository (https://seer.cancer.gov/).

\section{Statistical analysis}

Survival time was defined as the time period from diagnosis to the last follow-up or deaths due to all causes (overall survival, OS) or cancer-specific mortalities (cancer-specific survival, CSS). Pearson's chi-squared tests were used to assess the associations between clinicopathological characteristics and patient groups. A oneto-ten nearest propensity score matching (PSM) analysis with a caliper of 0.2 was performed by a logistic regression model, using the following characteristics as covariates: age, tumor site and grade, $\mathrm{T}$ and $\mathrm{N}$ stage, surgery, radiotherapy, and chemotherapy. The score-matched cohorts were used in the subsequent analyses. The cancerspecific mortality, non-cancer-specific mortality, and OS of patients with certain types of cancers were compared with those factors of patients without prior cancers. Cancer-specific and non-cancer-specific mortality were regarded as two competing events. Fine and Grey's model was used to estimate the subhazard ratios of variables in the analyses of overall mortalities and cancerspecific mortalities $[8,9]$. The Kaplan-Meier method was used to determine OS, and survival differences between groups were compared by the log-rank test. The hazard ratio (HR) and the associated 95\% confidence interval (CI) were also calculated.

Statistical analyses were performed using $\mathrm{R}$ software (v 3.4.2, The $\mathrm{R}$ Foundation for Statistical Computing, Vienna, Austria, http://www.r-project.org). A two-tailed $P$-value $<0.05$ was considered statistically significant.

\section{Results}

\section{Patient characteristics}

We initially identified 9235 patients with PDAC from the SEER database, including 438 (4.74\%) patients with a prior cancer and 8797 (95.26\%) patients without a prior cancer, and their baseline clinicopathological characteristics were compared (Table 1). In contrast to patients with prior cancer, those without cancer were younger, had a larger proportion of pancreatic head cancer, had a larger tumor, were in advanced TNM stages and were more likely to receive surgery and chemotherapy. To equilibrate these significantly different baseline characteristics, a PSM analysis was adopted. A total of 438 patients with prior cancers and 4380 patients without were matched, and the variables were balanced between these two groups. Among the 438 patients with a prior cancer, prostate cancer $(28.8 \%)$ was the most common initial tumor, followed by breast (25.1\%), renal and bladder (11.6\%), colon and rectum (9.8\%), uterine (5.5\%), lung (3.7\%), small intestinal (3.4\%), oral (3.0\%), stomach (2.7\%), and hepatocellular (1.8\%) cancer.

\section{Comparison of OS rates in patients with and without a prior cancer}

In the whole study cohort, the median OS rates during the follow-up period were 7 and 8 months for patients with and without prior cancer, respectively. In addition, 
Table 1 Comparisons of clinicopathological characteristics of patients

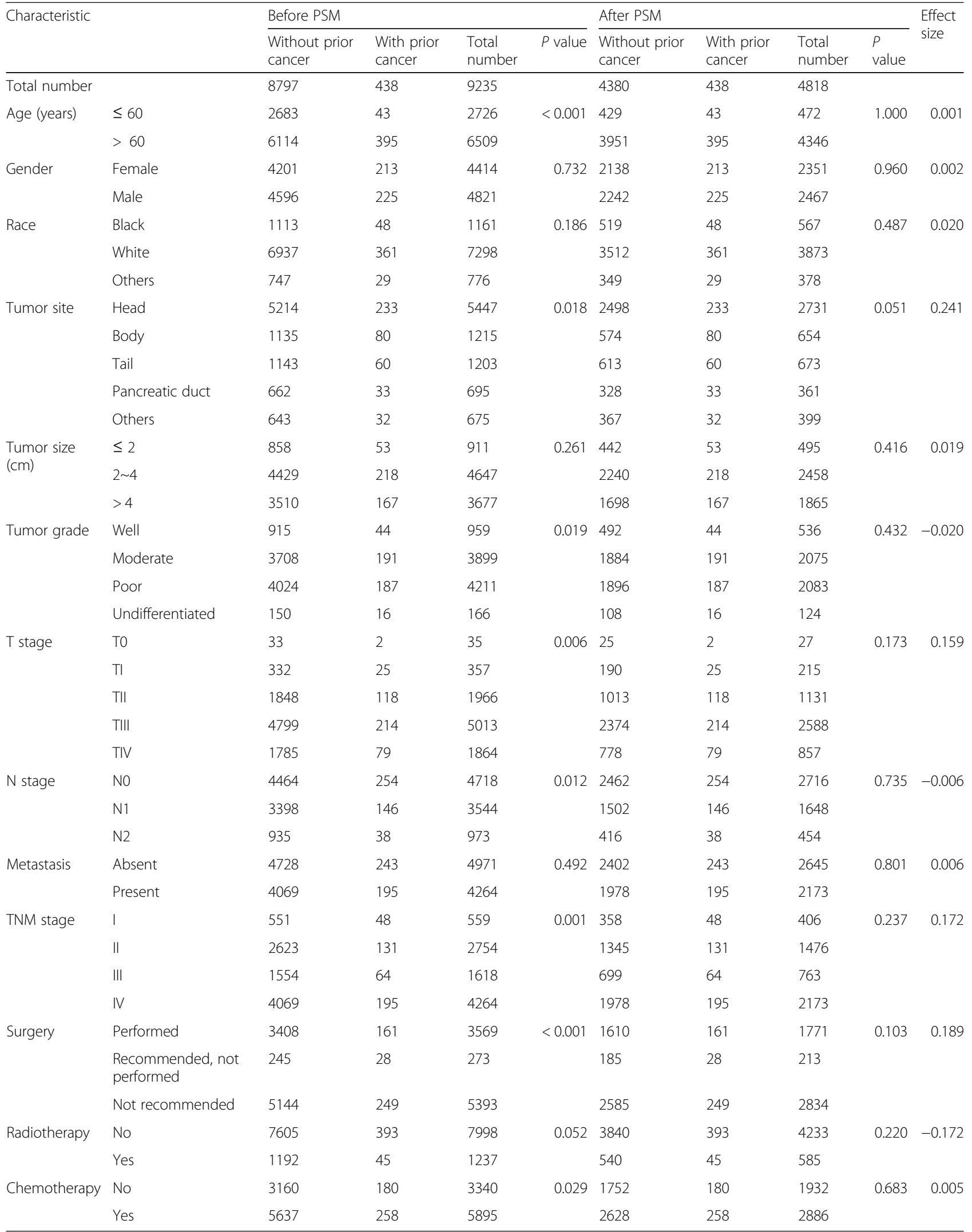


patients with and without a prior cancer had comparable survival rates after the PSM analysis. The 1-, 2-, and 3year OS rates were 35.3, 18.3, 10.9 and $35.1 \%, 18.1$, $11.7 \%$ for patients with and without a prior cancer, respectively (Table 2). When stratified by initial cancer sites, compared with patients without prior cancer, the survivors of prostate, lung, small intestinal, oral, stomach, and hepatocellular cancers had a slightly better short-term survival, and the survivors of other types of prior cancers had a slightly better long-term survival; however, these survival differences were not significant (Fig. 1). In addition, similar results were shown in the subgroup analyses of OS stratified by time interval among the whole cohort (Additional file 1: Table S1).

\section{Comparison of mortalities in patients with and without a prior cancer}

During the follow-up period, there were 296 (84.8\%) cancer-specific and 53 (15.2\%) non-cancer-specific mortalities in patients with a prior cancer. In patients without a prior cancer, 6578 (96.0\%) cancer-specific and 272 (4.0\%) non-cancer-specific mortalities were observed before the PSM analysis, and the 1-, 2-, and 3 -year overall, cancer-specific, and non-cancer-specific mortalities were $63.3,81.2$, and $88.3 \%$; 60.6, 77.8, and $84.4 \%$; $2.7,3.5$, and $3.8 \%$, respectively. After the PSM analysis, 3315 (95.7\%) cancer-specific and 150 (4.3\%) non-cancer-specific mortalities were observed. The 1-, $2-$, and 3-year overall, cancer-specific and non-cancerspecific mortalities are provided in Tables 2 and 3 . When stratified by initial cancer sites, the patients with a prior cancer had comparatively lower cancerspecific mortalities, although no significant differences were found. In addition, compared with patients without prior cancer, patients with a history of prostate, breast, renal and bladder, small intestinal, oral, or hepatocellular cancer had significantly more competing mortalities (Fig. 2).

Table 2 Cumulative incidences of mortality of patients

\begin{tabular}{|c|c|c|c|c|c|c|c|c|c|}
\hline \multirow[t]{2}{*}{ Cancer type } & \multirow[t]{2}{*}{ No } & \multicolumn{3}{|c|}{ Cancer-specific mortality (\%) } & \multirow[t]{2}{*}{$p^{a}$} & \multicolumn{3}{|c|}{ Non-cancer-specific mortality (\%) } & \multirow[t]{2}{*}{$p^{a}$} \\
\hline & & 1-year (95\% Cl) & 2-year (95\% Cl) & 3-year (95\% Cl) & & 1-year (95\% Cl) & 2-year (95\% Cl) & 3-year $(95 \% \mathrm{Cl})$ & \\
\hline Whole cohort & 9235 & $60.6(60.5-60.7)$ & 77.8(77.9-77.8) & $84.4(84.3-84.5)$ & & $2.7(2.6-2.8)$ & $3.5(3.4-3.6)$ & $3.8(3.7-3.9)$ & \\
\hline Without prior cancer & 8797 & $60.9(60.8-70.0)$ & $78.2(78.1-78.3)$ & 84.9(84.8-85.0) & & $2.3(2.2-2.4)$ & $3.0(2.9-3.1)$ & $3.3(3.2-3.4)$ & \\
\hline Prostate cancer & 126 & $59.5(59.1-59.9)$ & $69.6(69.3-70.0)$ & 80.8(80.5-81.1) & 0.237 & $9.1(9.0-9.2)$ & $12.1(11.9-12.3)$ & $12.1(11.9-12.3)$ & $<0.001$ \\
\hline Breast cancer & 110 & $62.4(61.9-62.9)$ & 78.6(78.1-79.1) & 84.7(84.2-85.2) & 0.029 & $5.8(5.6-6.0)$ & $8.3(8.1-8.5)$ & $8.3(8.1-8.5)$ & $<0.001$ \\
\hline Renal and bladder cancer & 51 & $52.2(51.1-53.3)$ & $64.1(63.1-65.1)$ & $72.1(71.0-73.1)$ & 0.067 & $12.2(11.2-13.2)$ & 14.6(13.6-15.6) & 14.6(13.6-15.6) & $<0.001$ \\
\hline Colon and rectal cancer & 43 & $60.5(59.3-61.6)$ & $75.4(74.5-76.3)$ & 78.4(77.5-79.3) & 0.746 & 9.3(8.9-9.7) & $9.3(8.9-9.7)$ & $9.3(8.9-9.7)$ & 0.033 \\
\hline Uterine cancer & 24 & 49.4(47.0-51.8) & $54.6(52.2-57.1)$ & $54.6(52.2-57.1)$ & 0.063 & $8.8(8.1-9.6)$ & $8.8(8.1-9.6)$ & $8.8(8.1-9.6)$ & 0.096 \\
\hline Lung cancer & 16 & $38.8(36.1-41.5)$ & $73.1(68.9-77.3)$ & 73.1(68.9-77.3) & 0.017 & 13.1(10.6-15.6) & 13.1(10.6-15.6) & $13.1(9.1-17.1)$ & $<0.001$ \\
\hline Small intestinal cancer & 15 & $42.0(38.2-45.8)$ & $53.7(36.6-67.4)$ & NA & 0.076 & $14.0(12.1-15.9)$ & $34.5(28.7-40.4)$ & NA & $<0.001$ \\
\hline Oral cancer & 13 & $40.4(36.1-44.7)$ & $75.0(71.1-78.9)$ & NA & 0.456 & $7.7(6.5-8.9)$ & $7.7(6.5-8.9)$ & NA & 0.008 \\
\hline Gastric cancer & 12 & $53.8(48.0-59.6)$ & $90.3(76.7-)$ & NA & 0.985 & $9.7(7.7-11.7)$ & $9.7(7.7-11.7)$ & NA & 0.204 \\
\hline Hepatocellular cancer & 8 & $50.0(42.3-57.7)$ & $62.5(54.2-70.8)$ & $62.5(54.2-70.8)$ & 0.217 & $12.5(9.4-15.6)$ & 25.0(18.9-31.1) & 25.0(18.9-31.1) & $<0.001$ \\
\hline Matched cohort & 4818 & 61.8(61.7-61.9) & 77.7(77.6-77.8) & 83.8(83.7-83.9) & & $3.1(3.0-3.2)$ & $4.1(4.0-4.2)$ & $4.5(4.4-4.6)$ & \\
\hline Without prior cancer & 4380 & $62.4(62.3-62.5)$ & 78.6(78.6-84.7) & $84.7(84.5-84.8)$ & & $2.4(2.3-2.5)$ & $3.2(3.1-3.3)$ & $3.6(3.5-3.7)$ & \\
\hline Prostate cancer & 126 & 59.5(59.1-59.9) & 69.6(69.3-70.0) & 80.8(80.5-81.1) & 0.173 & $9.1(9.0-9.2)$ & $12.1(11.9-12.3)$ & $12.1(11.9-12.3)$ & $<0.001$ \\
\hline Breast cancer & 110 & $62.4(61.9-62.9)$ & 78.6(78.1-79.1) & $84.7(84.2-85.2)$ & 0.074 & $5.8(5.6-6.0)$ & $8.3(8.1-8.5)$ & $8.3(8.1-8.5)$ & 0.001 \\
\hline Renal and bladder cancer & 51 & $52.2(51.1-53.3)$ & $64.1(63.1-65.1)$ & $72.1(71.0-73.1)$ & 0.051 & $12.2(11.2-13.2)$ & 14.6(13.6-15.6) & 14.6(13.6-15.6) & $<0.001$ \\
\hline Colon and rectal cancer & 43 & 60.5(59.3-61.6) & $75.4(74.5-6.3)$ & 78.4(77.5-79.3) & 0.654 & $9.3(8.9-9.7)$ & $9.3(8.9-9.7)$ & $9.3(8.9-9.7)$ & 0.058 \\
\hline Uterine cancer & 24 & 49.4(47.0-51.8) & $54.6(52.2-57.1)$ & $54.6(52.2-57.1)$ & 0.051 & $8.8(8.1-9.6)$ & $8.8(8.1-9.6)$ & $8.8(8.1-9.6)$ & 0.123 \\
\hline Lung cancer & 16 & $38.8(36.1-41.5)$ & $73.1(68.9-77.3)$ & $73.1(68.9-77.3)$ & 0.215 & 13.1(10.6-15.6) & 13.1(10.6-15.6) & $13.1(9.1-17.1)$ & 0.052 \\
\hline Small intestinal cancer & 15 & $42.0(38.2-45.8)$ & $53.7(36.6-47.4)$ & NA & 0.065 & $14.0(12.1-15.9)$ & $34.5(28.7-40.4)$ & NA & $<0.001$ \\
\hline Oral cancer & 13 & $40.4(36.1-44.7)$ & $75.0(71.1-78.9)$ & NA & 0.412 & $7.7(6.5-8.9)$ & $7.7(6.5-8.9)$ & NA & 0.013 \\
\hline Gastric cancer & 12 & 53.8(48.0-59.6) & $90.3(76.7-)$ & NA & 0.922 & $9.7(7.7-11.7)$ & $9.7(7.7-11.7)$ & NA & 0.238 \\
\hline Hepatocellular cancer & 8 & $50.0(42.3-57.7)$ & $62.5(54.2-70.8)$ & $62.5(54.2-70.8)$ & 0.207 & $12.5(9.4-15.6)$ & 25.0(18.9-31.1) & 25.0(18.9-31.1) & 0.001 \\
\hline
\end{tabular}

NA Not available, $\mathrm{Cl}$ Confidence interval

$p^{\mathrm{a}}$-values represented the differences of cancer-specific mortalities or non-cancer-specific mortalities between patients with certain kind of prior tumor and those without prior tumor 


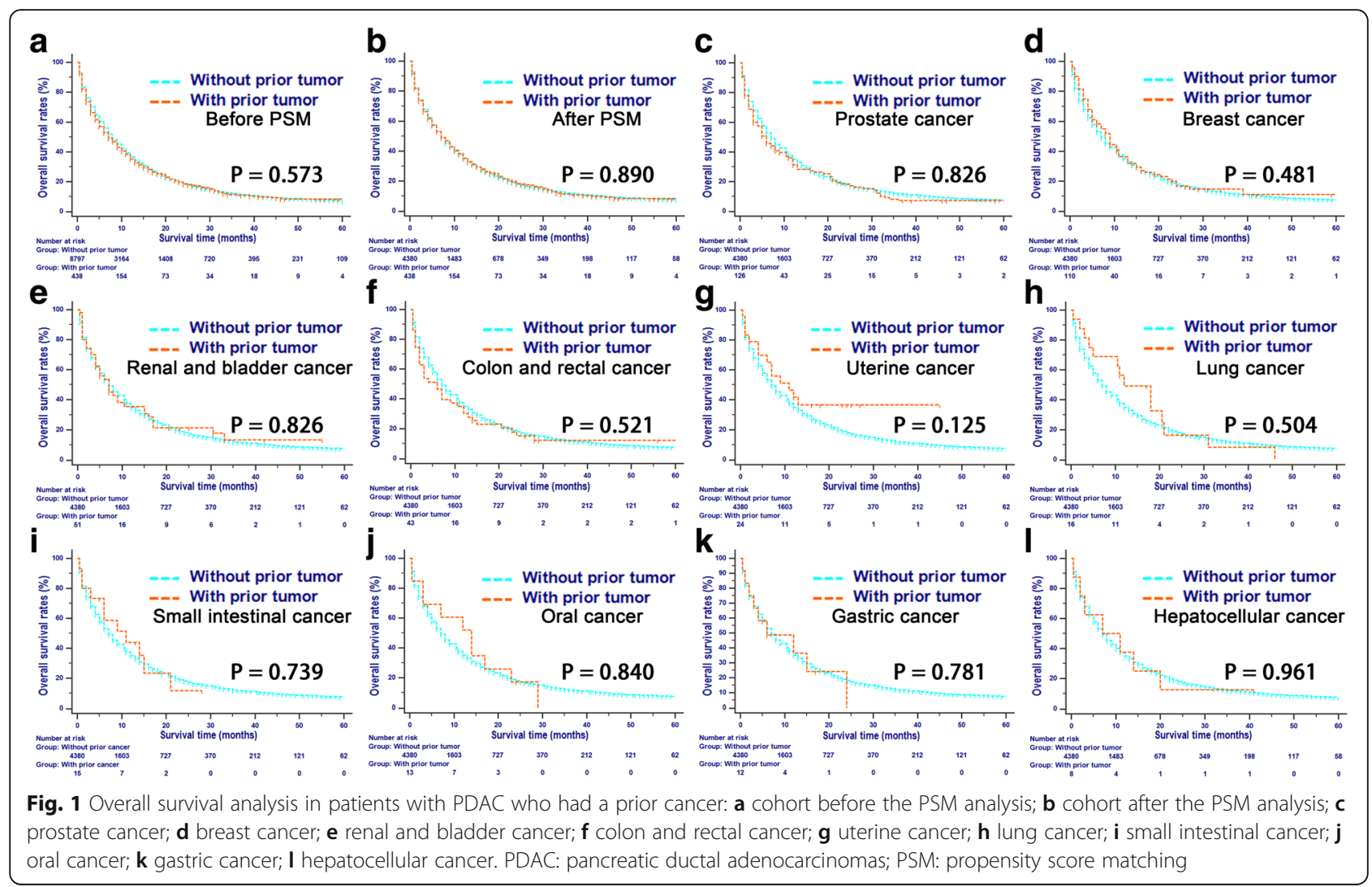

\section{Comparison of the OS rates separated by the time interval}

The overall median time interval from initial cancer to second primary cancer was 103.5 months. The time interval exceeded 60 months in patients with a history of prostate (97.0 months), breast (129.5 months), renal and bladder (68.0 months), colon and rectum (69.0 months), uterine (193.5 months), lung (65.5 months), small intestinal (94.0 months) or oral (127.0 months) cancer. It was shown in this study that there were some overlaps in the survival curves for patients with and without prior cancer, which indicated that the proportional hazards assumption was not satisfied. Similar to many clinical trials in which the 5-year time interval was used as an exclusion window [10], in this study, we adopted the 5year period as a cutoff value for the time interval from initial cancer to second primary cancer. There were 147 (33.6\%) PDACs that occurred within this time interval in patients with a prior cancer. There were no significant differences in OS for patients with and those without a prior cancer regardless of whether the PDAC occurred within or beyond the 5-year time interval (Table 4), with an exception for patients with a history of breast cancer. When PDAC occurred within the 5-year time interval, the patients with prior breast cancer had a significantly better survival compared with those without a prior cancer $(p<0.001)$. However, inferior survival was observed in patients who developed secondary PDAC occurring beyond the 5 -year time interval $(p<0.001)$.

\section{Univariate and multivariate analyses of OS}

The clinical and pathological variables were included in the univariate and multivariate analyses to identify the prognostic factors of OS. A history of prior cancer was not associated with OS in the study cohort before or after the PSM analysis. Variables such as tumor size and grade, $\mathrm{N}$ stage, metastasis, surgery, radiotherapy, and chemotherapy were identified as prognostic factors of OS for all patients, for those without a prior cancer, and for those with a prior cancer (Table 5, Additional file 2: Table S2 and Additional file 3: Table S3, respectively). Among patients with a prior cancer, there was no increase in the risk of decreased survival compared with those without a prior cancer.

\section{Discussion}

Over the last few decades, the dramatic improvement in the prognosis of many types of cancers has led to the increased development of a second primary cancer. Similar to other types of cancers $[7,10,11]$, PDAC is more and more frequently emerging as a second primary cancer. In this study, $4.74 \%$ of the patients with PDAC were accompanied with a prior cancer. Prostate, breast, and renal and bladder cancers were the three most 
Table 3 Overall survival rates of patients

\begin{tabular}{|c|c|c|c|c|c|c|}
\hline \multirow[t]{2}{*}{ Cancer type } & \multirow[t]{2}{*}{ No } & \multicolumn{3}{|c|}{ Overall survival rates (\%) } & \multirow[t]{2}{*}{ HR $(95 \%$ Cl) } & \multirow[t]{2}{*}{$p^{a}$} \\
\hline & & 1-year (95\% Cl) & 2-year (95\% Cl) & 3-year (95\% Cl) & & \\
\hline Whole cohort & 9235 & $36.7(36.6-36.7)$ & 18.7(18.6-18.7) & $11.7(11.6-11.7)$ & & \\
\hline Without prior cancer & 8797 & $36.8(36.7-36.9)$ & 18.7(18.6-18.8) & 11.7(11.6-11.8) & & \\
\hline Prostate cancer & 126 & $35.6(35.3-35.8)$ & $21.4(21.1-21.5)$ & $13.3(13.1-13.5)$ & 1.137(0.928-1.393) & 0.171 \\
\hline Breast cancer & 110 & $36.5(36.4-36.6)$ & $16.6(16.5-16.7)$ & $14.7(14.6-14.8)$ & $0.966(0.780-1.197)$ & 0.749 \\
\hline Renal and bladder cancer & 51 & $35.6(35.5-35.7)$ & $21.4(21.3-21.5)$ & 13.3(13.2-13.4) & 1.004(0.732-1.376) & 0.980 \\
\hline Colon and rectal cancer & 43 & $30.2(30.1-30.3)$ & 15.3(15.2-15.4) & $12.3(12.2-12.4)$ & $1.149(0.813-1.624)$ & 0.382 \\
\hline Uterine cancer & 24 & $41.8(41.6-42.0)$ & $36.6(36.4-36.8)$ & $36.6(36.4-36.8)$ & $0.700(0.451-1.086)$ & 0.165 \\
\hline Lung cancer & 16 & $49.2(49.0-49.4)$ & $16.4(16.2-16.6)$ & $8.2(8.1-8.4)$ & $0.865(0.531-1.408)$ & 0.572 \\
\hline Small intestinal cancer & 15 & $44.0(43.7-44.3)$ & $11.7(11.5-11.9)$ & $11.7(11.5-11.9)$ & $0.948(0.533-1.687)$ & 0.855 \\
\hline Oral cancer & 13 & $51.9(51.6-52.2)$ & $17.3(17.1-17.5)$ & 0.0 & $0.976(0.544-1.752)$ & 0.935 \\
\hline Gastric cancer & 12 & $36.5(36.2-36.8)$ & 0.0 & 0.0 & $1.150(0.571-2.318)$ & 0.663 \\
\hline Hepatocellular cancer & 8 & $37.5(37.2-37.8)$ & $12.5(12.3-12.7)$ & $12.5(12.3-12.7)$ & $1.014(0.481-2.138)$ & 0.971 \\
\hline Matched cohort & 4818 & $35.1(35.0-35.2)$ & $18.2(18.1-18.2)$ & 11.7(11.7-11.7) & & \\
\hline Without prior cancer & 4380 & $33.0(32.9-33.1)$ & 18.2(18.1-18.3) & $11.7(11.6-11.7)$ & & \\
\hline Prostate cancer & 126 & $35.6(35.3-35.5)$ & $21.4(21.1-21.5)$ & 13.3(13.1-13.5) & 0.967(0.708-1.318) & 0.826 \\
\hline Breast cancer & 110 & $36.5(36.4-36.6)$ & $16.6(16.5-16.7)$ & 14. (14.6-14.8) & $0.927(0.751-1.145)$ & 0.481 \\
\hline Renal and bladder cancer & 51 & $35.6(35.5-35.7)$ & $21.4(21.3-21.5)$ & 13.3(13.2-13.4) & 0.967(0.709-1.318) & 0.826 \\
\hline Colon and rectal cancer & 43 & $30.2(30.1-30.3)$ & $15.3(15.2-15.4)$ & $12.3(12.2-12.4)$ & $1.107(0.788-1.557)$ & 0.521 \\
\hline Uterine cancer & 24 & $41.8(41.6-42.0)$ & $36.6(36.4-36.8)$ & $36.6(36.4-36.8)$ & $0.676(0.439-1.041)$ & 0.125 \\
\hline Lung cancer & 16 & $49.2(49.0-49.4)$ & $16.4(16.2-16.6)$ & $8.2(8.048-8.352)$ & $0.842(0.520-1.364)$ & 0.504 \\
\hline Small intestinal cancer & 15 & $44.0(43.7-44.3)$ & $11.7(11.5-11.9)$ & $11.7(11.5-11.9)$ & 0.908(0.517-1.596) & 0.739 \\
\hline Oral cancer & 13 & $51.9(51.6-52.2)$ & $17.3(17.1-17.5)$ & 0.0 & 0.943(0.531-1.676) & 0.840 \\
\hline Gastric cancer & 12 & $36.5(36.2-36.8)$ & 0.00 & 0.0 & $1.093(0.552-2.167)$ & 0.781 \\
\hline Hepatocellular cancer & 8 & $37.5(37.2-37.8)$ & $12.5(12.3-12.7)$ & $12.5(12.3-12.7)$ & $0.982(0.471-2.010)$ & 0.961 \\
\hline
\end{tabular}

Cl Confidence interval

$p^{a}$-values represented the differences of overall survival rates between patients with certain kind of prior tumor and those without prior tumor

commonly observed types of prior cancers in patients with PDAC. A genetic predisposition, such as the mutation of BRCA2 [12, 13], and some environmental risk factors, such as alcohol, tobacco, and a lack of physical exercises [14], contributed to the excess risks of multiple cancers in patients with PDAC. In this study, the median time intervals from initial cancer to second primary PDAC were different for different types of cancers. The variations in time intervals suggest that it is necessary to screen for PDAC in cancer survivors and provide clues to guide screening strategies or screening intervals for patients with PDAC as a second primary cancer.

There is a widely accepted rule in clinical trials according to which patients with prior cancers are to be excluded. The assumption of prior cancers impacting survival outcomes contributes to this exclusion rule, which further limits the authenticity and generalizability of results of the clinical trials with this exclusion criterion [7]. Moreover, this assumption has not been proven on the basis of authoritative data, especially for patients with PDAC as a second primary cancer. In this study, compared with mortalities from prior cancers, more cancer-related mortalities were observed in patients with PDAC as a second primary tumor. In addition, patients with PDAC who had a prior cancer had a median survival of 7 months, which is comparable to that of patients with PDAC who did not have a prior cancer. Even after balancing the baseline characteristics using the PSM analysis, patients with PDAC with a prior cancer andthose without a prior cancer had almost overlapping survival curves and cumulative mortality curves, indicating that there was no negative impact on survival outcomes from prior cancers in patients with PDAC. Similar results were supported by studies in patients with lung cancer $[10,11]$. Moreover, when stratified by initial tumor sites, a possible long-term survival benefit and decreased cancer-specific mortalities were observed, especially in survivors of breast, colon and rectum, renal and bladder and uterine cancers, although the survival differences were not significant. These results indicated 


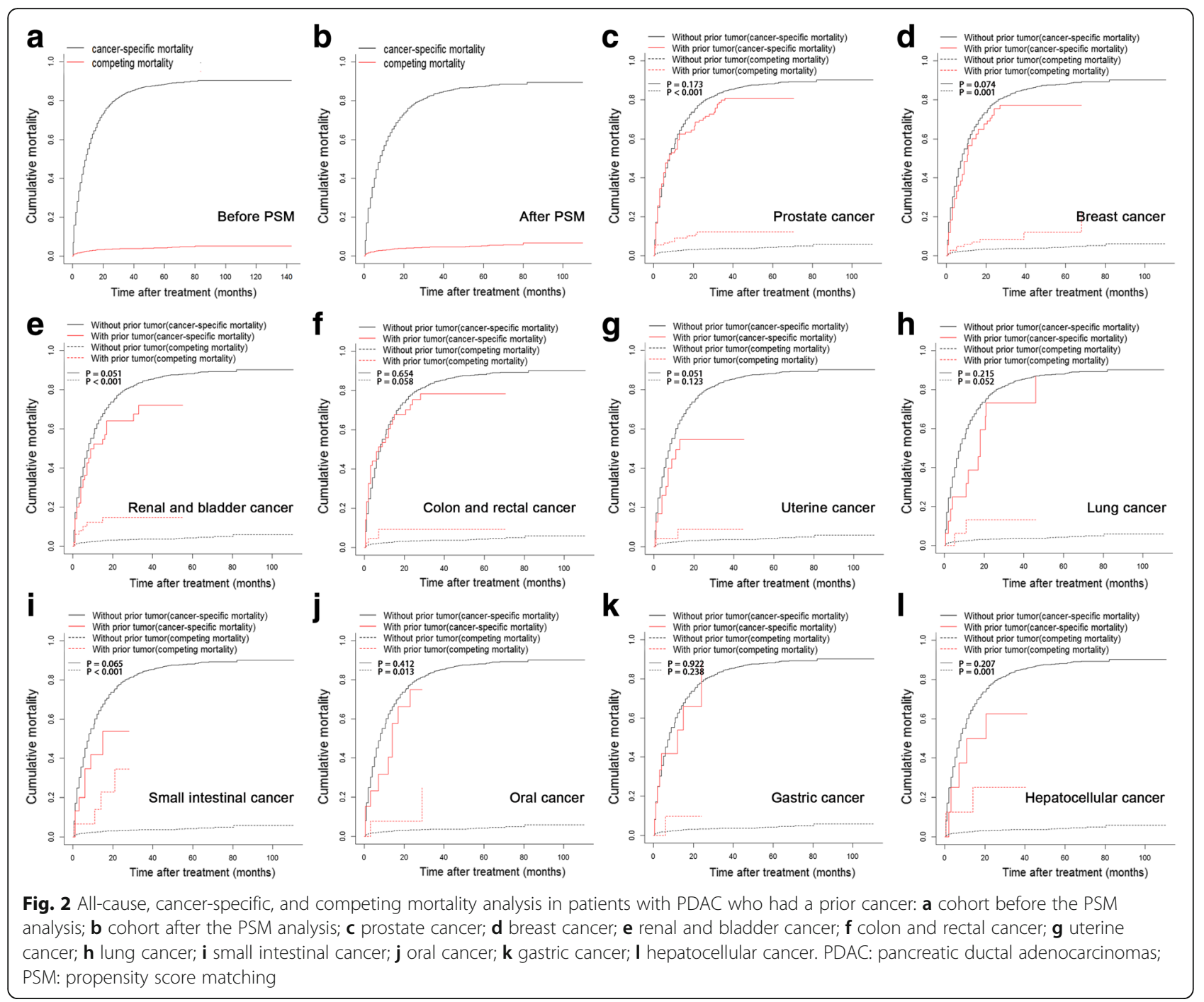

that certain types of prior cancers may result in improved rather than inferior survival outcomes in patients with PDAC. Interestingly, non-cancer-specific mortalities were higher in patients with certain types of prior cancers. It is possible that a smaller proportion of older patients contributed to this discrepancy.

Considering the importance of details regarding time intervals from initial cancer to second primary cancer, we adopted the 5-year time interval, which is often used as an exclusion window in clinical trials [10], as the cutoff value for the time interval in this study. When stratified by the time interval, different impacts of a prior cancer on survival were observed in patients with PDAC who initially had breast cancer. Compared to patients with PDAC who did not have a prior cancer, those with a prior cancer had better survival when PDAC developed within 5 years from the initial cancer, whereas a prior history indicated a negative effect on the survival of patients in whom PDAC developed later than within 5 years from the initial cancer. This discrepancy showed that the time interval was probably an important factor that should be considered when evaluating the prognostic impact of a history of cancer, especially in patients with breast tumors as the initial cancer. Except for breast cancer, a consistent survival effect and significance among the whole study cohort were observed for other types of prior cancers. For most types of prior cancers, survivors with PDAC had similar survival rates, regardless of the time interval within or beyond 5 years from their initial cancer diagnosis. This consistent effect and its significance were consistent with the results of previous cohort studies [7].

Time-dependent survival analyses further illustrated that a prior cancer had little impact on the survival of patients with PDAC. Consistent with our results, Zhou et al. also found that prior cancer did not have an adverse impact on the all-cause survival of patients with PDAC [7]. In addition, the independent prognostic 
Table 4 Subgroup analysis of prior cancer history impact on overall survival stratified by the time interval in matched cohort

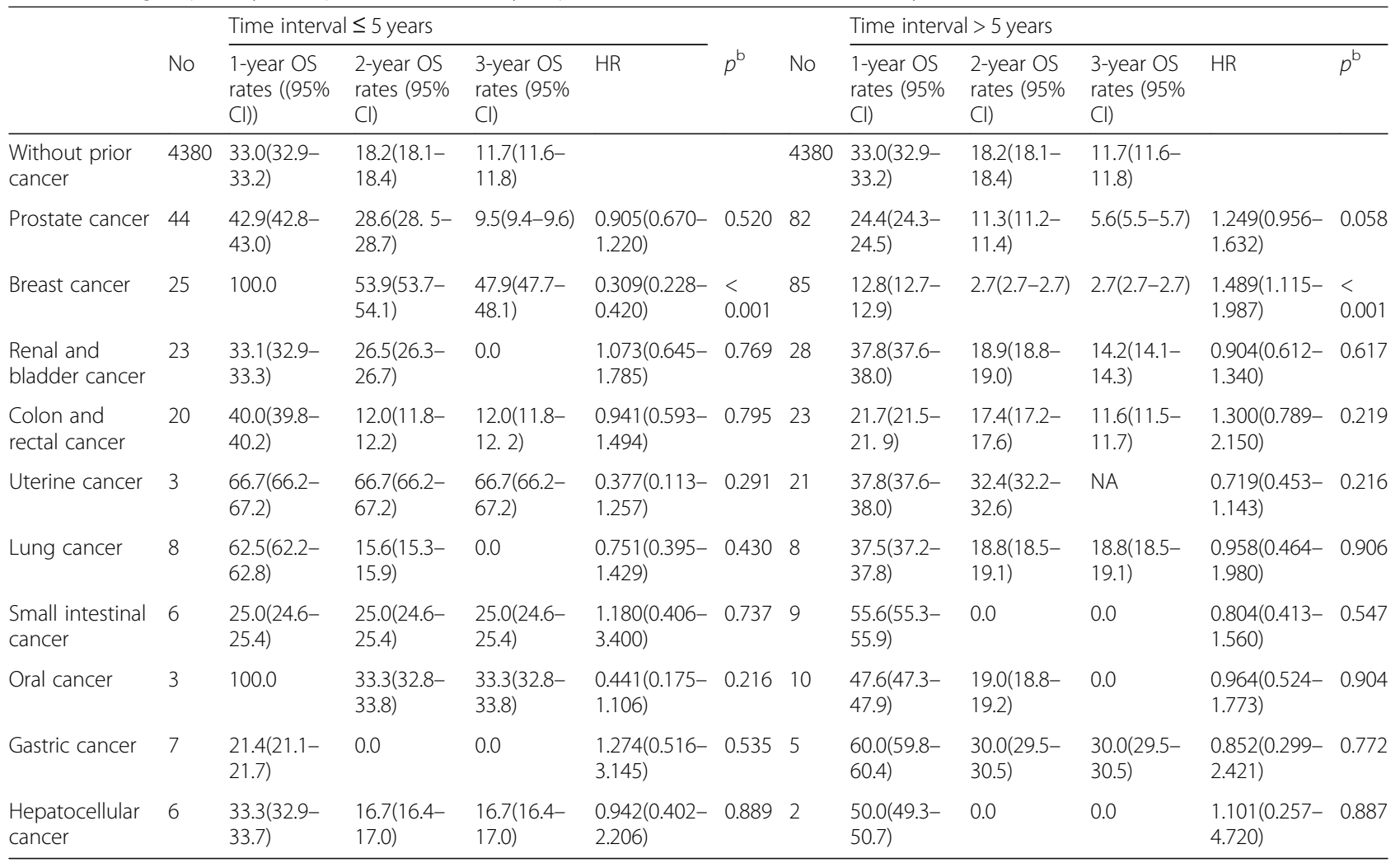

CI Confidence interval, HR Hazard ratio, NA Not available, OS Overall survival

$p^{b}$-values represented the differences of overall survival rates between patients with certain kind of prior tumor and those without prior tumor

factors for PDAC as the second primary cancer were similar to those for PDAC as the first primary tumor [15-18]. A history of prior cancer was not associated with OS for patients with PDAC. Potential explanations may include biological effects and regular follow-up examinations. First, PDAC that developed as a second primary cancer accounted for a small proportion of all cases of PDAC. The biologically independent nature and extremely high degree of malignancy made it responsible for most of the cancer-specific mortalities [6]. Second, regular routine follow-up after the diagnosis of an initial cancer contributed to the early diagnosis of subsequent PDAC. Additionally, the reduced exposure to risk factors such as alcohol and tobacco demonstrated a favorable prognosis for patients with PDAC. The differences between the matched population and true population might have led to some biases in the survival analyses, which was the weakness of this study. However, comparisons of the survival analyses showed that there were only small differences in survival between the matched and whole cohorts, which represented the true PDAC population. In addition, the risk factors identified in patients with and without prior cancer were almost the same. The comparisons of results on the basis of different cohorts can further illustrate that there was only a small impact of prior cancer in the survival analyses of patients with PDAC.

In the current study, there was only a small impact of prior cancer on OS and cancer-specific mortalities in patients with PDAC on the basis of a large study cohort. This finding inspired us to reevaluate the long-accepted assumption that a history of prior cancer was incorporated into the exclusion criteria in clinical trials. It is the first time that the survival impact of a prior cancer in patients with PDAC was investigated, and our study provides the data to address this issue as an exclusion criterion in clinical trials. The expanded inclusion criteria of patients with PDAC who had prior cancers would probably increase the accuracy and generalizability of the results from clinical trials.

There were several limitations to this study. First, the retrospective nature made it challenging to balance all the clinicopathological characteristics, even after the PSM analysis. Second, the information about prior cancers was limited. Apart from the sequence number and time interval of multiple cancers, some detailed clinicopathological features about the prior cancers were unavailable in the SEER dataset. In addition, the SEER dataset lacked detailed information on treatments, such as surgery, radiotherapy, and chemotherapy, and lifestyle 
Table 5 Univariate and multivariate analyses of OS

\begin{tabular}{|c|c|c|c|c|c|c|c|c|c|c|c|c|c|}
\hline \multirow[t]{3}{*}{ Characteristic } & & \multicolumn{6}{|c|}{ Before PSM } & \multicolumn{6}{|c|}{ After PSM } \\
\hline & & \multicolumn{3}{|c|}{ Univariate analysis } & \multicolumn{3}{|c|}{ Multivariate analysis } & \multicolumn{3}{|c|}{ Univariate analysis } & \multicolumn{3}{|c|}{ Multivariate analysis } \\
\hline & & $\mathrm{HR}$ & $95 \% \mathrm{Cl}$ & $p$ & $\mathrm{HR}$ & $95 \% \mathrm{Cl}$ & $p$ & $\mathrm{HR}$ & $95 \% \mathrm{Cl}$ & $p$ & $\mathrm{HR}$ & $95 \% \mathrm{Cl}$ & $p$ \\
\hline \multirow[t]{2}{*}{ Age (years) } & $\leq 60$ & \multicolumn{3}{|c|}{ Reference } & \multicolumn{3}{|c|}{ Reference } & \multicolumn{3}{|c|}{ Reference } & \multicolumn{3}{|c|}{ Reference } \\
\hline & $>60$ & 1.186 & $\begin{array}{l}1.128- \\
1.248\end{array}$ & $\begin{array}{l}< \\
0.001\end{array}$ & 1.203 & $\begin{array}{l}1.143- \\
1.267\end{array}$ & $\begin{array}{l}< \\
0.001\end{array}$ & 1.228 & $\begin{array}{l}1.101- \\
1.371\end{array}$ & $\begin{array}{l}< \\
0.001\end{array}$ & 1.150 & $\begin{array}{l}1.030- \\
1.284\end{array}$ & 0.013 \\
\hline \multirow[t]{2}{*}{ Gender } & Female & \multicolumn{3}{|c|}{ Reference } & & & $\mathrm{Nl}$ & \multicolumn{3}{|c|}{ Reference } & & & $\mathrm{Nl}$ \\
\hline & Male & 1.046 & $\begin{array}{l}0.999- \\
1.096\end{array}$ & 0.053 & & & & 1.011 & $\begin{array}{l}0.948- \\
1.077\end{array}$ & 0.746 & & & \\
\hline \multirow[t]{3}{*}{ Race } & Black & \multicolumn{3}{|c|}{ Reference } & \multicolumn{3}{|c|}{ Reference } & \multicolumn{3}{|c|}{ Reference } & \multicolumn{3}{|c|}{ Reference } \\
\hline & White & 0.905 & $\begin{array}{l}0.845- \\
0.970\end{array}$ & 0.005 & 0.934 & $\begin{array}{l}0.872- \\
1.002\end{array}$ & 0.056 & 0.898 & $\begin{array}{l}0.814- \\
0.991\end{array}$ & 0.032 & 0.931 & $\begin{array}{l}0.843- \\
1.028\end{array}$ & 0.156 \\
\hline & Others & 0.890 & $\begin{array}{l}0.804- \\
0.986\end{array}$ & 0.026 & 0.920 & $\begin{array}{l}0.830- \\
1.020\end{array}$ & 0.113 & 0.875 & $\begin{array}{l}0.755- \\
1.013\end{array}$ & 0.074 & 0.948 & $\begin{array}{l}0.818- \\
1.099\end{array}$ & 0.477 \\
\hline \multirow[t]{5}{*}{ Tumor site } & Head & \multicolumn{3}{|c|}{ Reference } & \multicolumn{3}{|c|}{ Reference } & \multicolumn{3}{|c|}{ Reference } & \multicolumn{3}{|c|}{ Reference } \\
\hline & Body & 1.363 & $\begin{array}{l}1.273- \\
1.461\end{array}$ & $\begin{array}{l}< \\
0.001\end{array}$ & 0.929 & $\begin{array}{l}0.865- \\
0.998\end{array}$ & 0.043 & 1.307 & $\begin{array}{l}1.188- \\
1.437\end{array}$ & $\begin{array}{l}< \\
0.001\end{array}$ & 0.966 & $\begin{array}{l}0.874- \\
1.066\end{array}$ & 0.489 \\
\hline & Tail & 1.412 & $\begin{array}{l}1.317- \\
1.513\end{array}$ & $\begin{array}{l}< \\
0.001\end{array}$ & 0.988 & $\begin{array}{l}0.919- \\
1.062\end{array}$ & 0.751 & 1.456 & $\begin{array}{l}1.326- \\
1.599\end{array}$ & $\begin{array}{l}< \\
0.001\end{array}$ & 1.039 & $\begin{array}{l}0.942- \\
1.146\end{array}$ & 0.443 \\
\hline & Pancreatic duct & 1.458 & $\begin{array}{l}1.336- \\
1.590\end{array}$ & $\begin{array}{l}< \\
0.001\end{array}$ & 0.995 & $\begin{array}{l}0.910- \\
1.089\end{array}$ & 0.921 & 1.483 & $\begin{array}{l}1.314- \\
1.674\end{array}$ & $\begin{array}{l}< \\
0.001\end{array}$ & 1.019 & $\begin{array}{l}0.899- \\
1.156\end{array}$ & 0.769 \\
\hline & Others & 1.424 & $\begin{array}{l}1.304- \\
1.555\end{array}$ & $\begin{array}{l}< \\
0.001\end{array}$ & 0.971 & $\begin{array}{l}0.886- \\
1.064\end{array}$ & 0.522 & 1.459 & $\begin{array}{l}1.299- \\
1.638\end{array}$ & $\begin{array}{l}< \\
0.001\end{array}$ & 0.931 & $\begin{array}{l}0.824- \\
1.053\end{array}$ & 0.254 \\
\hline \multirow{3}{*}{$\begin{array}{l}\text { Tumor size } \\
(\mathrm{cm})\end{array}$} & $\leq 2$ & Refere & ence & & Refere & ence & & Referer & nce & & Refere & ence & \\
\hline & $2 \sim 4$ & 1.429 & $\begin{array}{l}1.310- \\
1.559\end{array}$ & $\begin{array}{l}< \\
0.001\end{array}$ & 1.159 & $\begin{array}{l}1.034- \\
1.300\end{array}$ & 0.011 & 1.392 & $\begin{array}{l}1.238- \\
1.564\end{array}$ & $\begin{array}{l}< \\
0.001\end{array}$ & 1.215 & $\begin{array}{l}1.033- \\
1.430\end{array}$ & 0.019 \\
\hline & $>4$ & 2.162 & $\begin{array}{l}1.980- \\
2.361\end{array}$ & $\begin{array}{l}< \\
0.001\end{array}$ & 1.407 & $\begin{array}{l}1.252- \\
1.581\end{array}$ & $\begin{array}{l}< \\
0.001\end{array}$ & 2.127 & $\begin{array}{l}1.888- \\
2.397\end{array}$ & $\begin{array}{l}< \\
0.001\end{array}$ & 1.459 & $\begin{array}{l}1.236- \\
1.722\end{array}$ & $\begin{array}{l}< \\
0.001\end{array}$ \\
\hline Tumor grade & Well & Refere & ence & & Refere & nce & & Referer & nce & & Refere & ence & \\
\hline & Moderate & 1.116 & $\begin{array}{l}1.028- \\
1.212\end{array}$ & 0.009 & 1.233 & $\begin{array}{l}1.135- \\
1.339\end{array}$ & $\begin{array}{l}< \\
0.001\end{array}$ & 1.030 & $\begin{array}{l}0.923- \\
1.148\end{array}$ & 0.599 & 1.204 & $\begin{array}{l}1.078- \\
1.345\end{array}$ & 0.001 \\
\hline & Poor & 1.601 & $\begin{array}{l}1.476- \\
1.736\end{array}$ & $\begin{array}{l}< \\
0.001\end{array}$ & 1.584 & $\begin{array}{l}1.459- \\
1.719\end{array}$ & $\begin{array}{l}< \\
0.001\end{array}$ & 1.412 & $\begin{array}{l}1.267- \\
1.573\end{array}$ & $\begin{array}{l}< \\
0.001\end{array}$ & 1.446 & $\begin{array}{l}1.295- \\
1.615\end{array}$ & $\begin{array}{l}< \\
0.001\end{array}$ \\
\hline & Undifferentiated & 1.697 & $\begin{array}{l}1.416- \\
2.034\end{array}$ & $\begin{array}{l}< \\
0.001\end{array}$ & 1.357 & $\begin{array}{l}1.131- \\
1.628\end{array}$ & 0.001 & 1.633 & $\begin{array}{l}1.320- \\
2.019\end{array}$ & $\begin{array}{l}< \\
0.001\end{array}$ & 1.377 & $\begin{array}{l}1.111- \\
1.707\end{array}$ & 0.004 \\
\hline T stage & TO & Refere & ence & & Refere & ence & & Referer & nce & & Refere & ence & \\
\hline & $\mathrm{T} 1$ & 0.200 & $\begin{array}{l}0.139- \\
0.287\end{array}$ & $\begin{array}{l}< \\
0.001\end{array}$ & 0.334 & $\begin{array}{l}0.231- \\
0.483\end{array}$ & $\begin{array}{l}< \\
0.001\end{array}$ & 0.250 & $\begin{array}{l}0.164- \\
0.380\end{array}$ & $\begin{array}{l}< \\
0.001\end{array}$ & 0.374 & $\begin{array}{l}0.242- \\
0.577\end{array}$ & $\begin{array}{l}< \\
0.001\end{array}$ \\
\hline & T2 & 0.471 & $\begin{array}{l}0.335- \\
0.661\end{array}$ & $\begin{array}{l}< \\
0.001\end{array}$ & 0.451 & $\begin{array}{l}0.313- \\
0.650\end{array}$ & $\begin{array}{l}< \\
0.001\end{array}$ & 0.547 & $\begin{array}{l}0.370- \\
0.807\end{array}$ & 0.002 & 0.480 & $\begin{array}{l}0.311- \\
0.742\end{array}$ & 0.001 \\
\hline & T3 & 0.288 & $\begin{array}{l}0.205- \\
0.404\end{array}$ & $\begin{array}{l}< \\
0.001\end{array}$ & 0.444 & $\begin{array}{l}0.309- \\
0.638\end{array}$ & $\begin{array}{l}< \\
0.001\end{array}$ & 0.351 & $\begin{array}{l}0.238- \\
0.517\end{array}$ & $\begin{array}{l}< \\
0.001\end{array}$ & 0.483 & $\begin{array}{l}0.313- \\
0.743\end{array}$ & 0.001 \\
\hline & $\mathrm{T} 4$ & 0.480 & $\begin{array}{l}0.342- \\
0.674\end{array}$ & $\begin{array}{l}< \\
0.001\end{array}$ & 0.450 & $\begin{array}{l}0.313- \\
0.648\end{array}$ & $\begin{array}{l}< \\
0.001\end{array}$ & 0.578 & $\begin{array}{l}0.391- \\
0.855\end{array}$ & 0.006 & 0.462 & $\begin{array}{l}0.299- \\
0.714\end{array}$ & $\begin{array}{l}< \\
0.001\end{array}$ \\
\hline N stage & No & Refere & ence & & Refere & ence & & Referer & nce & & Refere & ence & \\
\hline & N1 & 0.925 & $\begin{array}{l}0.881- \\
0.971\end{array}$ & 0.002 & 1.100 & $\begin{array}{l}1.046- \\
1.156\end{array}$ & $\begin{array}{l}< \\
0.001\end{array}$ & 0.905 & $\begin{array}{l}0.845- \\
0.969\end{array}$ & 0.004 & 1.096 & $\begin{array}{l}1.021- \\
1.176\end{array}$ & 0.011 \\
\hline & N2 & 0.591 & $\begin{array}{l}0.544- \\
0.641\end{array}$ & $\begin{array}{l}< \\
0.001\end{array}$ & 1.396 & $\begin{array}{l}1.268- \\
1.537\end{array}$ & $\begin{array}{l}< \\
0.001\end{array}$ & 0.575 & $\begin{array}{l}0.511- \\
0.647\end{array}$ & $\begin{array}{l}< \\
0.001\end{array}$ & 1.408 & $\begin{array}{l}1.226- \\
1.616\end{array}$ & $\begin{array}{l}< \\
0.001\end{array}$ \\
\hline Metastasis & Absent & Refere & ence & & Refere & ence & & Referer & nce & & Refere & ence & \\
\hline & Present & 2.874 & $\begin{array}{l}2.739- \\
3.015\end{array}$ & $\begin{array}{l}< \\
0.001\end{array}$ & 1.702 & $\begin{array}{l}1.608- \\
1.802\end{array}$ & $\begin{array}{l}< \\
0.001\end{array}$ & 2.911 & $\begin{array}{l}2.723- \\
3.112\end{array}$ & $\begin{array}{l}< \\
0.001\end{array}$ & 1.719 & $\begin{array}{l}1.589- \\
1.859\end{array}$ & $\begin{array}{l}< \\
0.001\end{array}$ \\
\hline
\end{tabular}


Table 5 Univariate and multivariate analyses of OS (Continued)

\begin{tabular}{|c|c|c|c|c|c|c|c|c|c|c|c|c|c|}
\hline \multirow[t]{3}{*}{ Characteristic } & & \multicolumn{6}{|c|}{ Before PSM } & \multicolumn{6}{|c|}{ After PSM } \\
\hline & & \multicolumn{3}{|c|}{ Univariate analysis } & \multicolumn{3}{|c|}{ Multivariate analysis } & \multicolumn{3}{|c|}{ Univariate analysis } & \multicolumn{3}{|c|}{ Multivariate analysis } \\
\hline & & $\mathrm{HR}$ & $95 \% \mathrm{Cl}$ & $p$ & $\mathrm{HR}$ & $95 \% \mathrm{Cl}$ & $p$ & $\mathrm{HR}$ & $95 \% \mathrm{Cl}$ & $p$ & $\mathrm{HR}$ & $95 \% \mathrm{Cl}$ & $p$ \\
\hline \multirow[t]{3}{*}{ Surgery } & Performed & \multicolumn{3}{|c|}{ Reference } & \multicolumn{3}{|c|}{ Reference } & \multicolumn{3}{|c|}{ Reference } & \multicolumn{3}{|c|}{ Reference } \\
\hline & $\begin{array}{l}\text { Recommended, not } \\
\text { performed }\end{array}$ & 3.367 & $\begin{array}{l}2.948- \\
3.846\end{array}$ & $\begin{array}{l}< \\
0.001\end{array}$ & 2.570 & $\begin{array}{l}2.232- \\
2.959\end{array}$ & $\begin{array}{l}< \\
0.001\end{array}$ & 3.365 & $\begin{array}{l}2.881- \\
3.929\end{array}$ & $\begin{array}{l}< \\
0.001\end{array}$ & 2.626 & $\begin{array}{l}2.221- \\
3.105\end{array}$ & $\begin{array}{l}< \\
0.001\end{array}$ \\
\hline & Not recommended & 3.431 & $\begin{array}{l}3.255- \\
3.618\end{array}$ & $\begin{array}{l}< \\
0.001\end{array}$ & 2.608 & $\begin{array}{l}2.419- \\
2.813\end{array}$ & $\begin{array}{l}< \\
0.001\end{array}$ & 3.582 & $\begin{array}{l}3.323- \\
3.861\end{array}$ & $\begin{array}{l}< \\
0.001\end{array}$ & 2.684 & $\begin{array}{l}2.416- \\
2.982\end{array}$ & $\begin{array}{l}< \\
0.001\end{array}$ \\
\hline \multirow[t]{2}{*}{ Radiotherapy } & No & \multicolumn{3}{|c|}{ Reference } & \multicolumn{3}{|c|}{ Reference } & \multicolumn{3}{|c|}{ Reference } & \multicolumn{3}{|c|}{ Reference } \\
\hline & Yes & 0.369 & $\begin{array}{l}0.341- \\
0.399\end{array}$ & $\begin{array}{l}< \\
0.001\end{array}$ & 0.887 & $\begin{array}{l}0.813- \\
0.969\end{array}$ & 0.008 & 0.369 & $\begin{array}{l}0.330- \\
0.412\end{array}$ & $\begin{array}{l}< \\
0.001\end{array}$ & 0.860 & $\begin{array}{l}0.759- \\
0.974\end{array}$ & 0.017 \\
\hline \multirow[t]{2}{*}{ Chemotherapy } & No & \multicolumn{3}{|c|}{ Reference } & \multicolumn{3}{|c|}{ Reference } & \multicolumn{3}{|c|}{ Reference } & \multicolumn{3}{|c|}{ Reference } \\
\hline & Yes & 0.445 & $\begin{array}{l}0.425- \\
0.467\end{array}$ & $\begin{array}{l}< \\
0.001\end{array}$ & 0.435 & $\begin{array}{l}0.414- \\
0.457\end{array}$ & $\begin{array}{l}< \\
0.001\end{array}$ & 0.450 & $\begin{array}{l}0.422- \\
0.480\end{array}$ & $\begin{array}{l}< \\
0.001\end{array}$ & 0.451 & $\begin{array}{l}0.422- \\
0.483\end{array}$ & $\begin{array}{l}< \\
0.001\end{array}$ \\
\hline \multirow[t]{2}{*}{ Prior cancer } & Without & \multicolumn{3}{|c|}{ Reference } & \multicolumn{3}{|c|}{ Reference } & \multicolumn{3}{|c|}{ Reference } & \multicolumn{3}{|c|}{ Reference } \\
\hline & With & 1.030 & $\begin{array}{l}0.925- \\
1.147\end{array}$ & 0.587 & 1.014 & $\begin{array}{l}0.910- \\
1.130\end{array}$ & 0.796 & 0.993 & $\begin{array}{l}0.889- \\
1.108\end{array}$ & 0.894 & 1.018 & $\begin{array}{l}0.912- \\
1.136\end{array}$ & 0.754 \\
\hline
\end{tabular}

OS Overall survival, $H R$ Hazard ratio

factors, such as body mass index and smoking status. Third, although the total number of patients with PDAC who had prior cancers was relatively large, cases of a certain type of cancer represented a small proportion of patients. In addition, the matched cohort selected by the PSM analysis did not represent the true PDAC population; therefore, there might be some biases in the survival analyses, which should be addressed. A larger cohort study is needed to confirm the results of this study.

\section{Conclusions}

In conclusion, our study evaluated the prognostic impact of prior cancer in patients with PDAC. The history of a prior cancer caused no significant differences in the overall survival or cancer-specific mortality rates. The inclusion of patients with a prior cancer in the clinical trials of PDAC should be considered. However, further studies are needed to confirm these results.

\section{Additional files}

Additional file 1: Table S1. Subgroup analysis of the impact of a prior cancer on overall survival stratified by the time interval from the prior diagnosis among the whole cohort. This table shows the survival differences between patients without prior cancer and those with different kinds of cancers. (DOCX $19 \mathrm{~kb}$ )

Additional file 2: Table S2. Univariate and multivariate analyses of overall survival in patients without prior cancer. This table shows the significant predictors of overall survival in patients without prior cancer. (DOCX $23 \mathrm{~kb}$ )

Additional file 3: Table S3. Univariate and multivariate analyses of overall survival in patients with a prior cancer. This table shows the significant predictors of overall survival in patients with a prior cancer. (DOCX $20 \mathrm{~kb}$ )

\section{Abbreviations}

Cl: Confidence interval; CSS: Cancer-specific survival; HR: Hazard ratio; OS: Overall survival; PDAC: Pancreatic ductal adenocarcinoma;

PSM: Propensity score matching; SEER: Surveillance, Epidemiology, and End Results; SPM: Second primary malignant neoplasms; TNM: Tumor-nodemetastasis

\section{Acknowledgements}

The authors would like to thank SEER for open access to database.

\section{Authors' contributions}

$\mathrm{CBH}$ and $\mathrm{YZ}$ contributed to this work equally. $\mathrm{XJL}$ was responsible for conception, design and quality control of this study. $\mathrm{CBH}$ and $\mathrm{YZ}$ performed the study selection, data extraction, statistical analyses, and was major contributors in writing the manuscript. $Y Z$ and $Z Y C$ participated in studies selection and statistical analyses. $C B H, Y Z$ and $X J L$ contributed in classification criteria discussion. $\mathrm{CBH}$ and $\mathrm{YZ}$ contributed to the writing of manuscript. XJL reviewed and edited the manuscript respectively. All authors read and approved the final manuscript.

\section{Funding}

This study was supported by the funding of Sun Yat-sen University Grant for Medical Humanities Practice and Teaching (No. 23000-18008023). The funding bodies had no role in the design of the study and collection, analysis, and interpretation of data and in the writing of the manuscript.

\section{Availability of data and materials}

The dataset from SEER database generated and/or analyzed during the current study are available in the SEER dataset repository (https://seer.cancer. gov/).

\section{Ethics approval and consent to participate}

This study was approved by the Institutional Review Board of Sun Yat-sen University Cancer Center. All procedures performed in studies involving human participants were in accordance with the ethical standards of the institutional and/or national research committee and with the 1964 Helsinki Declaration and its later amendments or comparable ethical standards. Written informed consent was obtained from individual participants included in the study. All authors signed authorization forms and received permission from SEER to access and use the dataset.

\section{Consent for publication}

Not applicable. 


\section{Competing interests}

The authors declare that they have no competing interests.

\section{Author details}

'Department of Hepatobiliary and Pancreatic Surgery, State Key Laboratory of Oncology in South China, Collaborative Innovation Center for Cancer Medicine, Sun Yat-sen University Cancer Center, Guangzhou 510060, People's Republic of China. ${ }^{2}$ State Key Laboratory of Ophthalmology, Zhongshan Ophthalmic Center, Sun Yat-sen University, Guangzhou, Guangdong 510060, People's Republic of China.

Received: 8 January 2019 Accepted: 23 May 2019

Published online: 29 May 2019

\section{References}

1. Siegel RL, Miller KD, Jemal A. Cancer statistics, 2018. CA Cancer J Clin. 2018; 68(1):7-30.

2. Donin N, Filson C, Drakaki A, Tan HJ, Castillo A, Kwan L, Litwin M, Chamie K. Risk of second primary malignancies among cancer survivors in the United States, 1992 through 2008. Cancer. 2016;122(19):3075-86.

3. Wood ME, Vogel V, Ng A, Foxhall L, Goodwin P, Travis LB. Second malignant neoplasms: assessment and strategies for risk reduction. J Clin Oncol : official journal of the American Society of Clinical Oncology. 2012;30(30): 3734-45.

4. Morton LM, Onel K, Curtis RE, Hungate EA, Armstrong GT. The rising incidence of second cancers: patterns of occurrence and identification of risk factors for children and adults. American Society of Clinical Oncology educational book American Society of Clinical Oncology Annual Meeting. 2014;10(1):e57-67.

5. Amin S, McBride RB, Kline JK, Mitchel EB, Lucas AL, Neugut Al, Frucht $H$. Incidence of subsequent pancreatic adenocarcinoma in patients with a history of nonpancreatic primary cancers. Cancer. 2012;1 18(5):1244-51.

6. Shen M, Boffetta P, Olsen JH, Andersen A, Hemminki K, Pukkala E, Tracey E, Brewster DH, McBride ML, Pompe-Kirn V, et al. A pooled analysis of second primary pancreatic cancer. Am J Epidemiol. 2006;163(6):502-11.

7. Zhou H, Huang Y, Qiu Z, Zhao H, Fang W, Yang Y, Zhao Y, Hou X, Ma Y, Hong $S$, et al. Impact of prior cancer history on the overall survival of patients newly diagnosed with cancer: a pan-cancer analysis of the SEER database. Int J Cancer. 2018;143(7):1569-77.

8. Gray RJ. A class of K-sample tests for comparing the cumulative incidence of a competing risk. Ann Stat. 1988;16(3):1141-54.

9. Fine JP, Gray RJ. A proportional hazards model for the subdistribution of a competing risk. J Am Stat Assoc. 1999;94(446):496-509.

10. Gerber DE, Laccetti AL, Xuan L, Halm EA, Pruitt SL. Impact of prior cancer on eligibility for lung cancer clinical trials. J Natl Cancer Inst. 2014;106(11):1-6.

11. Laccetti AL, Pruitt SL, Xuan L, Halm EA, Gerber DE. Effect of prior cancer on outcomes in advanced lung cancer: implications for clinical trial eligibility and accrual. J Natl Cancer Inst. 2015;107(4):1-9.

12. Brentnall TA. Management strategies for patients with hereditary pancreatic cancer. Curr Treat Options in Oncol. 2005;6(5):437-45.

13. Slater EP, Langer P, Fendrich V, Habbe N, Chaloupka B, Matthai E, Sina M, Hahn SA, Bartsch DK. Prevalence of BRCA2 and CDKN2a mutations in German familial pancreatic cancer families. Familial Cancer. 2010;9(3):335-43.

14. Barone E, Corrado A, Gemignani F, Landi S. Environmental risk factors for pancreatic cancer: an update. Arch Toxicol. 2016;90(11):2617-42

15. He C, Li S. 191PNomogram to predict cancer-specific survival in patients with pancreatic acinar cell carcinoma: a competing risk analysis. Ann Oncol. 2018;29(suppl_9):mdy432.043.

16. He C, Mao Y, Wang J, Huang X, Lin X, Li S. Surgical management of periampullary adenocarcinoma: defining an optimal prognostic lymph node stratification schema. J Cancer. 2018;9(9):1667-79.

17. He C, Zhang Y, Cai Z, Lin X, Li S. Overall survival and cancer-specific survival in patients with surgically resected pancreatic head adenocarcinoma: a competing risk nomogram analysis. J Cancer. 2018;9(17):3156-67.

18. He C, Mao Y, Wang J, Duan F, Lin X, Li S. Nomograms predict long-term survival for patients with periampullary adenocarcinoma after pancreatoduodenectomy. BMC Cancer. 2018;18(1):327.

\section{Publisher's Note}

Springer Nature remains neutral with regard to jurisdictional claims in published maps and institutional affiliations.

\section{Ready to submit your research? Choose BMC and benefit from:}

- fast, convenient online submission

- thorough peer review by experienced researchers in your field

- rapid publication on acceptance

- support for research data, including large and complex data types

- gold Open Access which fosters wider collaboration and increased citations

- maximum visibility for your research: over $100 \mathrm{M}$ website views per year

At BMC, research is always in progress.

Learn more biomedcentral.com/submissions 